\title{
PANORAMA ARTÍSTICO CHILENO DURANTE LA SEGUNDA MITAD DEL SIGLO XIX: DEBATES, INSTITUCIONALIDAD Y PROTAGONISTAS
}

\author{
PANORAMA OF THE CHILEAN ARTS DURING THE SECOND \\ HALF OF THE 19TH CENTURY: DEBATES, INSTITUTIONALITY, \\ AND MAIN FIGURES
}

\section{PEDRO EMILIO ZAMORANO** PATRICIA HERRERA STYLES ${ }^{* * * *}$}

\section{RESUMEN}

El escenario estético-visual chileno durante la segunda mitad del siglo XIX se caracterizó por la presencia de algunos artistas que ejercieron un fuerte liderazgo y ascendiente. A este respecto los ejemplos más paradigmáticos fueron José Miguel Blanco y Pedro Lira, en cuya relación es posible advertir un trasfondo de disputas y protagonismos que alinean a artistas y otros actores de la institucionalidad cultural. De este modo, en un escenario estético estrecho, relativamente estandarizado por una impronta grosso modo académica, las desavenencias ocuparon un lugar no menor, tanto en los procesos institucionales como en el registro escritural. En este contexto de confrontaciones pesaron tanto las visiones y protagonismos personales, como las diferencias ideológico-estéticas.

Palabras clave: Artes visuales en Chile, institucionalidad, crítica y debates.

\section{ABSTRACT}

The Chilean visual-aesthetics scenario during the second half of 19th century was characterised by the presence of some artists of strong leadership and influence. In this regard, the most paradigmatic examples were José Miguel Blanco and Pedro Lira, in

* Este artículo está inserto en el Proyecto de Investigación "Ausencia de una política o política de la ausencia. Institucionalidad y desarrollo de las artes visuales en Chile 1849-1973", Fondecyt $\mathrm{N}^{\circ} 1140370$. Investigador Responsable Pedro Emilio Zamorano Pérez. Coinvestigadores Claudio Cortés y Alberto Madrid, 2014-2016. Investigadora asociada Patricia Herrera Styles.

** Dr. en Historia del Arte, Profesor Titular Universidad de Talca. Talca, Chile. Correo electrónico: pzamoper@utalca.cl

*** Magíster en Estudios Latinoamericanos, Universidad de Playa Ancha. Valparaíso, Chile. Correo electrónico: patyhest@yahoo.com 
whose relation it is possible to perceive the background of arguments and prominence that line up artists as well as other actors of the cultural institutionality. Thus, in under a narrow aesthetic scenario, relatively standardised by an academic grosso modo impression, the disagreements took an important place both in the institutional processes as well as in the writing record. In the context of confrontations, the visions and personal prominence were as important as the aesthetic-ideological differences.

Keywords: Visual arts in Chile, institutionality, critics, debates.

Recibido: 21.04.15. Aceptado: 28.07.15.

\section{ANTECEDENTES}

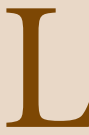

A INFORMACIÓN y escritura artística en nuestro país, durante el siglo XIX y primeras décadas del XX, estuvo condicionada por diferentes factores que predeterminaron su naturaleza y formas de expresión. A este respecto hay varias cosas que señalar. En relación a los soportes de circulación podemos decir que, en general y quizá con la excepción de $E l$ Taller Ilustrado, no hubo medios especializados en el tema, sino más bien periódicos con información miscelánea, con mayor o menor sensibilidad y presencia respecto del fenómeno estético. De otra parte, las voces teóricas presentaban similar heterogeneidad en su formación y argumentaciones. Las había desde diletantes y personas cultas de la elite social, con un conocimiento cultural provisto, las más de las veces, por sus viajes o experiencias en el terreno de la diplomacia; hasta artistas - pintores y escultores- que incursionaron, con mayor o menor éxito, en el espacio escritural. El escenario era estrecho y estaba caracterizado por la presencia del Estado, que valoraba las tradiciones artísticas europeas, y por la adhesión a un modelo más bien tradicional que representaba la sensibilidad de la clase dirigente del país. Este paradigma -con sus reelaboraciones e interpretaciones locales- era sustentado por distintas entidades corporativas como la Unión Artística o la Comisión de Bellas Artes y, principalmente, por las instancias institucionales de formación como la Academia de Pintura y luego la de Escultura. En este contexto surgen algunas voces que se yerguen como autoridad en la materia; una suerte de comunicadores y defensores del "buen gusto" de una sociedad que entendía lo foráneo como un valor en sí mismo. En un escenario como éste, fueron los personalismos los que adquirieron muchas veces una cierta hegemonía sobre la institucionalidad y el debate teórico. De este modo la escritura se desligaba, en ocasiones, del fundamento estético para ir derechamente a la contingencia. 
En un escenario estrecho y, a veces, tensionado, no necesaria o exclusivamente por ideas o convicciones estéticas, las desavenencias ocupan un lugar importante, afectando el sistema artístico nacional (institucionalidad-enseñanza-escritura-patrimonio). Estos desencuentros tenían distintos orígenes y connotaciones. A modo de ejemplo, la confrontación generacional que ha alineado tradicionalmente a los jóvenes con el revisionismo en tanto que a los mayores con posiciones más conservadoras, tuvo en nuestro medio menos fuerza que otros elementos que venían condicionando de manera más decidida el debate artístico local, entre ellos la diferencia de clase. Artistas tales como Pedro Lira, Enrique Swimburn, José Tomás Errázuriz y el crítico Vicente Grez provenían del sector social más acomodado. La contraparte estaba constituida por pintores y escultores que procedían de sectores sociales medios e incluso bajos -recordemos el origen de Nicanor Plaza, José Miguel Blanco y Virginio Arias-, con menos incidencia social y contactos con la esfera gubernamental. No hablamos de una lucha de clases declarada, sino de elementos exógenos que condicionaron y tensionaron el debate ${ }^{1}$.

El aprendizaje en las instancias de formación local -la Academia de Pintura y Clase de Escultura e instituciones posteriores- y luego las experiencias de estudio en el extranjero que muchos de los artistas recibieron propició una relativa estandarización de los conceptos formales y de los repertorios iconográficos que suscribieron ${ }^{2}$. El Estado, principal ordenador del campo cultural, no fue neutral frente a estas circunstancias. Además de favorecer a aquellos que sintonizaban mejor con su mirada, concedía a algunos artistas y teóricos, sea por sus méritos o niveles de influencia social, un estatus hegemónico: la "voz autorizada". Bajo esta connotación se concibe la figura del artista o el crítico oficial. Este reconocimiento informal otorgado por el sector oficial no siempre traducía consensos o reconocimientos de los pares artísticos. Esta circunstancia tensionaba la convivencia y proveía de argumentos extraestéticos al debate.

\footnotetext{
${ }^{1}$ Conocida fue también la pertenencia a la Logia Masónica de los artistas Pedro Lira, Nicanor Plaza, José Miguel Blanco, Manuel Antonio Caro, entre otros.

${ }^{2}$ Diferente es el caso, décadas más tarde, de los pintores de la generación convenida en llamar como del Trece o del Centenario, en donde la experiencia vital de sus integrantes se transforma en argumento de sus creaciones pictóricas. Una fuerte iconografía de raigambre social aparece en la obra de Arturo Gordon, los hermanos Alfredo, Alberto y Enrique Lobos Aránguiz, Exequiel Plaza, Enrique Moya y Abelardo Bustamante, entre otros.
}

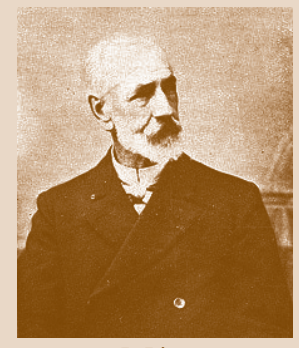

P. Lira

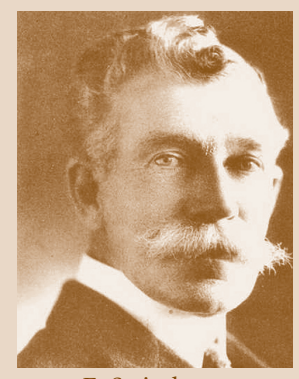

E. Swimburn

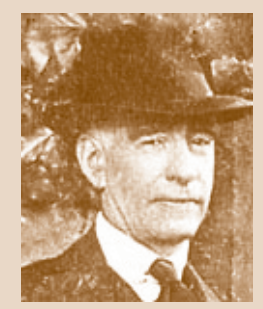

J. T. Errázuriz

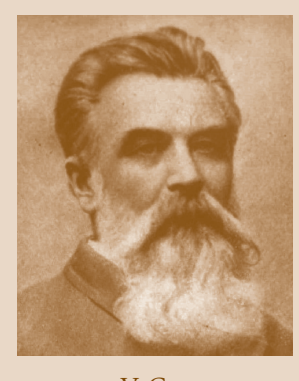

V. Grez 


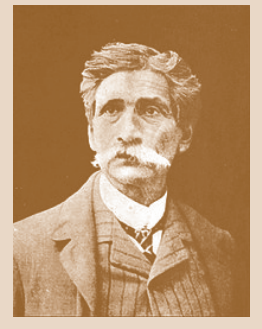

N. Plaza

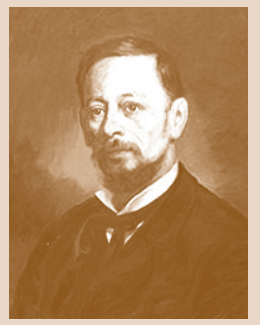

J. M. Blanco

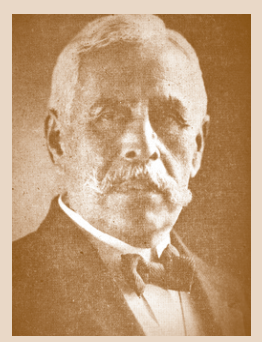

V. Arias

En este orden de ideas podemos señalar a Pedro Lira (1845-1912) -figura central en algunos desencuentros- como uno de los artistas más influyentes durante la segunda mitad del siglo XIX. El pintor exhibía sobrados méritos en las distintas facetas que cultivó; la calidad de su obra pictórica, su aporte a la institucionalidad artística, su condición de maestro, además de sus contribuciones en el campo teórico ${ }^{3}$. Lira, además, formaba parte del sector oligarca del país, que detentaba una clara hegemonía sobre el discurso público. Ungido informalmente como figura emblemática -según Richon Brunet (1912, p. 60) pretendía ejercer una autoridad moral en el arte chileno-, sin embargo, sus actuaciones no estuvieron exentas de polémica. A decir de Balmaceda Toro (1889, p. 51): "Tiene enerjía, franqueza, estudio, mucho estudio i mucha ciencia... pero, en cambio, el maestro es un tanto desgraciado, i tiene la rara condición de perder a sus alumnos". Esta posición "oficial", en el terreno de la reflexión teórica, fue detentada además por Vicente Grez (1847-1909), escritor con una obra diversa, que abordó también el fenómeno estético. El compromiso que este crítico tuvo con el modelo académico queda explicitado en la apología que hizo de pintores como Pedro Lira y Raimundo Monvoisin en "Les beaux arts au Chili" (Grez, 1889). De otra parte, en la decisión de nombrar a Grez como secretario de la Comisión Organizadora de la representación de Chile en la Exposición Universal de París de 1889 estaban implícitas las responsabilidades curatoriales que se le asignaban. En esta decisión el Estado le concedía la dignidad de "voz oficial". Un gesto similar hizo el Gobierno años más tarde, en 1910, cuando nombró a Alberto Mackenna Subercaseaux y al crítico y pintor francés Ricardo Richon Brunet como actores de primera línea en la organización de la Exposición del Centenario. Estos personajes fueron ungidos informalmente por la oficialidad del país como factótum; los depositarios y promotores de algunos conceptos, frecuentes de encontrar en los escritos de la época, entre ellos "buen gusto", "sanas tradiciones", entre otros.

\section{LA PRESENCIA DEL ESCULTOR JOSÉ MIGUEL BLANCO}

Como hemos señalado, la actividad artística en nuestro país durante el siglo XIX estuvo supeditada, en una parte por las directrices del Estado y por

\footnotetext{
${ }^{3}$ El aporte más relevante de Lira en el plano teórico está en su Diccionario biográfico de pintores (1902), Santiago de Chile, Imprenta Encuadernación y Litografías Esmeralda.
} 
el rol de las elites ilustradas que actuaron, en este ámbito, de consuno con la oficialidad. Todas estas instancias y actores -el "campo del poder", como diría Pierre Bourdieu (2002, p. 319)- constituyen una suerte de contraparte -el otro espacio- en el desarrollo artístico del país.

En este escenario había poco lugar para la disidencia; sin embargo, frente a ello, el escultor José Miguel Blanco (1839-1897) levantó una voz crítica desde las páginas de El San Lunes, "periódico literario, artístico i noticioso", creado por él, y luego desde El Taller Ilustrado, primer periódico dedicado a la difusión exclusiva del arte y del cual Blanco fue director y editor a partir de 1885. Este medio, que apoyó decididamente el desarrollo artístico local, también se dio espacio para criticar y denunciar el funcionamiento de algunas entidades que organizaban la actividad artística en el país. A modo de ejemplo, parte de sus objeciones apuntaba a las prerrogativas y el funcionamiento que tenía la Unión Artística ${ }^{4}$, institución que a pesar de su naturaleza privada, según Blanco, había adquirido un protagonismo excesivo y poco transparente en la organización de los salones oficiales. A decir de Josefina de la Maza (2010, p. 290), los reglamentos elaborados por la Unión para las exposiciones realizadas entre 1885 y 1887 beneficiaban fundamentalmente a los "compadres" y socios de la agrupación.

José Miguel Blanco, que inicialmente había aplaudido las actividades de la entidad, entre ellas la construcción del nuevo edificio para el Museo conocido como El Partenón, con posterioridad criticó con vehemencia su accionar desde las páginas de El Taller Ilustrado. Se erigen aquí dos bandos que entran en disputa. Uno, liderado por Pedro Lira y los miembros de la Unión Artística, que fundaron junto al crítico Vicente Grez la revista $E l$ Salón. Otro, que reunía a aquellos que adherían a la figura del escultor ${ }^{5}$. La crítica de este último apuntaba a los Salones realizados en El Partenón. Refiriéndose al Salón de 1887 señala: "El salón hizo fiasco desde su estreno. Hoi la Sociedad 'Unión Artística', con la conciencia 'del deber cumplido', se disuelve o se retira a la vida privada, cediendo graciosamente al Supre-

\footnotetext{
${ }^{4}$ En 1885 se había fundado la "Sociedad Anónima Unión Artística”, más conocida como Unión Artística, por Pedro Lira y varios coleccionistas y aficionados al arte pertenecientes a la elite.

${ }^{5}$ Entre los cercanos a Lira se encontraban figuras como Ramón Subercaseaux, diplomático, político y pintor, el crítico Vicente Grez, sus cuñados, Augusto y Alberto Orrego Luco, el pintor Onofre Jarpa y sus discípulos Rafael Correa, Alberto Valenzuela Llanos y Celia Castro, entre otros. En torno a Blanco se aglutinaban artistas e intelectuales de otro origen social como Pascual Ortega, Miguel Campos, Cosme San Martín, Alfredo Valenzuela Puelma, Ernesto Molina y el arquitecto Fermín Vivaceta, entre otros.
} 
mo Gobierno el Salón-estufa -léase el edificio del Museo- por la modesta suma de dieciséis mil pesos" (Blanco, 1887). Efectivamente, en un decreto firmado por el Presidente Balmaceda, de fecha 11 de febrero de 1887, se autorizaba al Director del Tesoro para reducir a Escritura Pública el contrato de venta del edificio. Blanco estimó que, de acuerdo a las condiciones que se establecían, los salones quedarían siempre bajo la dirección más o menos directa de su fundador (Lira).

El conflicto entre el pintor y el escultor no cesaría por un largo tiempo. En El Taller Ilustrado del 13 de mayo de 1889, Blanco, con profunda ironía, aplaude el nombramiento hecho por el Ministro de Justicia e Instrucción Pública de Pedro Lira como miembro de la Comisión Directiva de Bellas Artes. El escultor, con igual sorna, lamenta que en nuestro país no haya, como en Francia, un ministerio especial de Bellas Artes, en donde se nombre a Lira como ministro y a Grez como subsecretario. Advierte sobre la actitud totalitaria de Lira y del sentido clasista que imperan en sus decisiones y procedimientos: "Lira ha nacido para mandar, como Grez ha nacido para obedecer. Ambos se complementarían. Lira, reconociendo su impotencia para lucir las innatas aspiraciones de mando en la capa social a que pertenece, resolvió 'descender' a los hombres de trabajo, con la seguridad de lograr sus fines. Hoi en el colmo de sus deseos, puede plajiar al monarca francés esclamando: 'El arte soi yo"' (Blanco, 1889a).

Aun cuando Lira había declinado ser miembro de la Comisión dos años antes, por presentar conflictos de interés respecto de su participación en los salones -según consta en carta de su puño y letra dirigida al Ministro de Instrucción Pública- ${ }^{6}$, de igual forma Blanco sospechaba de su participación el peligro de una gestión arbitraria, antojadiza, a favor exclusivo de sus conveniencias y redes sociales. El escultor advertía acerca de los poderes que el Estado confería en este nombramiento al pintor, entendiendo la decisión como una injerencia desmedida en todos los aspectos relativos a la enseñanza, la circulación y adquisición de obras, la asignación de becas para los artistas, entre otros aspectos. El escultor percibía a Lira como la manzana de la discordia y como un enemigo de todos aquellos que no inclinaban la cabeza ante su obra y su figura intelectual.

Otro punto en conflicto entre ambos maestros dice relación con la crea-

\footnotetext{
6 "Sr. Ministro: Tengo el honor de comunicar a Ud. que me es imposible aceptar el nombramiento de miembro de la Comisión directiva de bellas artes, porque la situación que ese puesto me crearía sería incompatible con mi participación en los concursos que puedan sobrevenir i en que tengo la intención de presentarme como artista". Pedro Lira, Carta al Ministro de Instrucción Pública, Santiago, 20 abril 1887, Archivo Nacional, Fondo Ministerio de Educación, vol. 685.
} 
ción del Museo. Como se sabe, con posterioridad al proyecto de Miguel Luis Amunátegui de crear una Galería Histórica de Pintura en 1876, Blanco, en 1879, había planteado la necesidad de crear en Chile un Museo de Bellas Artes (Blanco, 1879). La idea fue acogida por el gobierno del Presidente Aníbal Pinto, quien, con fecha 31 de julio de 1880, nombró una comisión compuesta por el coronel Marcos Maturana, el pintor Giovanni Mochi y Blanco, para que organizaran el Museo de Pinturas. La comisión tenía como objetivo, además de reunir las obras, conformar un inventario con los cuadros y obras escultóricas.

El Museo fue inaugurado en el segundo piso del Congreso Nacional por el Presidente Pinto, el 18 de septiembre de 1880. Consumada la creación del Museo, Arturo Blanco (1912, p. 18), hijo del escultor, hace una fuerte demanda de gratitud hacia su padre, señalando que ni siquiera fue reconocido como "portero de la obra que él había formado".

Lira, por su parte, tuvo desde el principio una actitud crítica en relación al Museo organizado por Blanco, calificándolo de lugar "ignorado e incompleto" (Lira, 1883), ya que consideraba inadecuado tanto el espacio como la colección de obras que allí se exhibían (Herrera, 2014).

Las desavenencias entre ambos artistas tenían historia y connotaciones de distinta naturaleza. Blanco, el "estatuario", hizo presente en reiteradas ocasiones una supuesta deuda de gratitud de parte del Estado chileno hacia su persona. Esta falta de reconocimiento, como sostiene Carvacho (1983, p. 187), se evidenció luego de su regreso de Europa, cuando no recibió ningún puesto de trabajo oficial como se le había prometido.

De otra parte, al parecer, sí hubo de algunas autoridades la intención que Blanco asumiera como profesor en la Clase de Escultura a su regreso de París, según consta en carta enviada por Ignacio Domeyko -entonces rector de la Universidad de Chile- al ministro de Instrucción Pública, en junio de 1874, a poco más de un año antes de que el escultor regresara del Viejo Continente 7 . Sin embargo, esto nunca ocurrió, como de hecho sí había sucedido con la mayoría de los artistas becados quienes, a su regreso, ocuparon cargos académicos en la Escuela. Otra de las promesas hechas a Blanco había sido que, en su calidad de grabador de medallas formado en París sería contratado en la Casa de Moneda de Chile, cuestión que, como señala su hijo Arturo (1912, p. 15), finalmente tampoco se concretó. Las ra-

\footnotetext{
7 “A esta ocasión, me tomo la libertad de proponer a U.S. (...) nombre a D. Nicolás Romero, suplente de la clase de escultura, hasta que vuelva de Europa el pensionista Blanco, a quien me parece, corresponderá el desempeño de dicha clase..." (Domeyko, 1874).
} 
zones de esta marginación sistemática parecen ser varias, entre ellas la postura política y social que había asumido el escultor. Permeado, quizá, por la sensibilidad de su amigo Fermín Vivaceta, hay información que después de su regreso de Europa Blanco participó en instancias que promovían iniciativas obreras y de representación popular. Entre ellas se sabe, por ejemplo, que desde 1877 perteneció a la Sociedad de Artesanos La Unión y en 1879 fue miembro de la comisión redactora de El Taller, periódico obrero.

Finalmente, tanto José Miguel Blanco como su hijo Arturo siempre culparon a Lira -y en cierto grado también a Vicente Grez- como el responsable oculto de muchos de los problemas y postergaciones que le aquejaron. A este respecto, Arturo Blanco escribió de puño y letra: "El canalla de Lira, ni siquiera nombró a mi padre como iniciador y fundador del Museo"s.

\section{DEBATE ENTRE NICANOR PLAZA, PEDRO LIRA Y VIRGINIO ARIAS}

En los inicios de 1874 el escultor Nicanor Plaza (1841-1918) obtuvo del Supremo Gobierno los permisos necesarios para alejarse transitoriamente de la Escuela, con vistas al viaje que pretendía realizar a Europa y, según Pereira Salas (1992, p. 97), también "Para disponer de los materiales apropiados y disfrutar del descanso necesario para la creación”. De este modo, en los primeros meses de ese año Plaza ejecuta su segundo viaje a París. Previamente había realizado gestiones ante el ministro de Instrucción Pública, José María Barceló, con el propósito de conseguir una pensión en beneficio de Virginio Arias (1855-1941), su discípulo, con el objetivo que pudiera viajar a Europa a perfeccionar sus estudios?.

No habiendo prosperado en la solicitud, Plaza resolvió llevar al joven escultor a sus expensas, financiándole los gastos de estadía y estudio en París. A decir de Arturo Blanco (1930, p. 216), si no hubiese sido por Plaza se habría perdido el talento de Arias, como fue el caso de otros escultores tales como Agustín Depassier, Alejo Valdés, José Luengo, Aurelio Medina, entre otros.

El apoyo estatal para financiar becas en el extranjero a los escultores, al parecer, no fue tan generoso como lo había sido con los pintores. De hecho,

\footnotetext{
${ }^{8}$ Manuscrito en poder de Pedro Emilio Zamorano.

9 Según Plaza: "A principios de 1874 debía partir a Europa a ejecutar allá algunos trabajos, y habiendo notado en mi alumno Virginio Arias mui buenas condiciones para la escultura, me empeñé con el Ministro de Justicia, señor Barceló, para que se mandara a mi alumno a estudiar a Europa por cuenta del Estado. Todos mis esfuerzos en este sentido fueron estériles y no solamente no se aceptó mi proposición sino que no se me dio ninguna esperanza”. Información en El Ferrocarril, 25 de diciembre de 1892.
} 
desde la pensión que se le concedió a José Miguel Blanco, en 1867, hasta 1888, en que fue enviado Simón González, transcurrieron veintiún años sin que el gobierno concediera este beneficio a un escultor. En Francia el joven Arias siguió trabajando junto a su profesor y, en 1875, estando todavía al lado de su maestro, logró ser admitido en el Salón de París, con un busto en bronce, tomado del natural, del propio don Nicanor, quien financió la fundición de la pieza.

\section{EL DEBATE}

La iniciativa del maestro, muy encomiable, fue, sin embargo, objetada por Pedro Lira, quien sugirió que Plaza más que ayudar al desarrollo artístico de su discípulo, estaba consiguiendo ayuda para realizar los encargos que le había encomendado el gobierno y que debía realizar en Europa. En el periódico El Ferrocarril del 25 de diciembre de 1892, Plaza hace una serie de descargos frente a imputaciones que le había hecho Lira. Al parecer hubo una campaña, liderada por este pintor, que pretendía demostrar que el gesto de Plaza, de llevar a su discípulo a Europa, tenía como finalidad llevar "mano de obra" local barata para colaborar en la ejecución de las esculturas que el gobierno había encomendado a Plaza ${ }^{10}$. Otra de las acusaciones que se le hizo a Plaza fue que había dejado abandonado a su discípulo en París. $\mathrm{Al}$ respecto Plaza reconoce que a su regreso a Chile, a fines de septiembre de 1875, dejó a su discípulo en la Ciudad Luz con los recursos necesarios como para sobrevivir en condiciones de dignidad ${ }^{11}$. El propio don Virginio

${ }^{10}$ Frente a ello el escultor hace sus descargos: "Es sabido de algunas personas que el único propósito que tuve al llevar a Arias a Europa fue tan solo para que se perfeccionase en sus estudios y no perdiese su porvenir, dotando a la vez a mi país de un buen escultor, y volverme a Europa, como lo pensaba entonces, a continuar mi carrera artística, interrumpida en 1871. Si no hubiera sido así ¿qué garantías hubiera podido darme Arias de lo que iba a gastar por él? ¿Para qué necesitaba llevar empleado, a costa de tantos gastos y de sacrificios, a un joven que no sabía ni una palabra de francés, a entenderse en esa gran ciudad como la de París, completamente estraña para él, entre jente tan viva, tan ilustrada i tan versada en los negocios?". Agregando: "Arias no tuvo, pues, participación alguna en esos trabajos y sólo se ocupó de estudiar francés que yo en nuestro viaje me había esmerado en inculcarle; en modelar en greda y en mármol para perfeccionarse". Aparecido en El Ferrocarril, 25 de diciembre de 1872.

11 "Lo único que hay de verdad en todos estos cargos y quejas, es lo de la pequeña cantidad de doscientos francos que dejé a mi alumno, a mi vuelta a Chile (fines de septiembre de 1875) pero debo advertir que antes de volverme, habíale comprado los muebles necesarios y alquilédole un cuarto que se pagaba por trimestres. Quedaba pues tranquilo e independiente en una casa. Habíale comprado la ropa necesaria i regalándole mi reloj de oro, y sobre todo lo dejé muy recomendado a mi antiguo profesor Monsieur Joufroy". El Ferrocarril, 25 de diciembre de 1892. 
desmentiría años más tarde a su maestro, dando cuenta de las difíciles condiciones por las que tuvo que pasar en Europa por el incumplimiento de las promesas que le había hecho su maestro ${ }^{12}$.

\section{LA POLÉMICA ENTRE LIRA Y ARIAS}

Posteriormente, ya en los inicios del nuevo siglo, Lira también se enfrenta con quien tanto había defendido y de quien durante muchos años se consideró "amigo": el mismo Virginio Arias. En esta ocasión, la razón fue que Lira -quien ejerció de manera no oficial el cargo de director de la Escuela de Bellas Artes durante algunos años- se opuso al nombramiento y gestión de Arias como director del plantel, cargo que le había sido encomendado al escultor a partir de 1900. Los desencuentros, por cierto, no se limitaron solo al ámbito de la Escuela, sino que se ampliaron a otros espacios como los salones, el Museo y la prensa. En este conflicto terciaron, de una parte, Lira junto a la Comisión Directiva de Bellas Artes y un grupo de artistas que lo secundan, mientras que, de otra, Virginio Arias y varios de los artistas que ejercían como profesores en la Escuela y otros afines a su pensamiento.

El clima de confrontación en el espacio de la Escuela llegó a tener ribetes dramáticos, entendiéndose como una especie de "guerra", tal como lo expresara el mismo Lira: “(...) yo soy siempre el blanco de las más soeces agresiones. Pero como cuento con ellas por el hecho de hallarnos en guerra, no me hacen grande impresión"13. A través de diferentes misivas de carácter personal hoy a nuestra disposición, se sabe que el pintor hablaba del grupo opositor como "lobos", "filisteos", "banda" o "negra camarilla artística", mientras que a Arias lo calificaba de "araucano" y "cacique", debido a su origen mapuche, señalando a sus acciones al interior de la Escuela como "disparates", "chambonadas" y "torpezas"14.

\footnotetext{
12 "Hace nueve años vine a Europa con nuestro escultor Plaza, bajo ciertas condiciones que después no se realizaron. Como un año después de mi llegada a esta ciudad quedé solo, abandonado i sin recursos... sufrí mucho, trabajando de día i de noche i viviendo en un cuartito situado cerca de las nubes, al cual entraba nieve en el invierno, pude reunir unos cuantos francos con cuyas economías compré el yeso i útiles necesarios para hacer el 'Roto chileno', que, como usted probablemente sabe obtuvo una mención honrosa en la Exposición de Bellas Artes". El Mercurio, 20 de febrero de 1883.

${ }^{13}$ Carta de Pedro Lira a Valenzuela Llanos, 24 de marzo de 1902, en Díaz (2010, p. 74).

${ }^{14}$ Estos apelativos constan en diferentes cartas de Pedro Lira a Alberto Valenzuela Llanos, entre 1897 y 1910, en Díaz (2010).
} 
Los Salones que se realizaban en septiembre de cada año en el Museo de Bellas Artes, y cuya organización estaba a cargo de la Comisión Directiva, también se vieron afectados por este clima de rencillas y enfrentamientos. El debate estaba instalado, cuestionándose los reglamentos, la constitución de los jurados, los premios y casi todos los aspectos relativos a su organización. A este respecto Pedro Lira, en carta a Alberto Valenzuela Llanos, entrega algunos detalles del Salón de 1901, señalando que la actuación del "araucano" había hecho lujo de "parcialidad y de bajeza"15.

Este clima de crispación fue advertido también cuando se incorporó, contratado por el Gobierno, en 1908, a la Escuela el pintor español Fernando Álvarez de Sotomayor. En sus memorias inéditas habla de un entorno de rencillas y de la conformación de dos bandos capitaneados, respectivamente, por Lira y el escultor Arias. En el documento recuerda a Lira con las siguientes palabras: "En su vejez, habiendo derrochado actividad y dinero, encuentra en frente un grupo de artistas que le hacen la guerra capitaneados por D. Virgilio (sic) Arias (escultor) y es precisamente la causa de que el Gobierno me contrate como tercero en discordia"16.

Los conflictos hacían eje no solo en cuestiones ideológico-estéticas, o en temas generacionales o, incluso, raciales (cacique, araucano, etc.). Si se mira la conformación aristócrata de ese "campo del poder", no resulta difícil inferir que detrás del conflicto entre ambos hubo más de alguna consideración en relación a temas de procedencia, costumbres y origen social. No olvidemos que el Estado y la sociedad oligarca chilena de la época, de la cual se sentía representante el pintor, tuvieron una fuerte injerencia en todos los procesos relativos con la enseñanza, la difusión y el patrimonio artístico.

Productos de estos enconados debates, Lira finalmente decide retirarse de la Escuela trasladándose como docente a la Universidad Católica de Chile.

\section{POLÉMICA SOBRE LA FOTOPINTURA}

Los debates sobre este procedimiento en la confección de cuadros habían ya enfrentado a José Miguel Blanco y Pedro Lira a finales de la década del ochenta. Recuérdese las críticas que el escultor realizó a Lira en El Taller

\footnotetext{
${ }^{15}$ Carta de Lira a Valenzuela Llanos, 10 septiembre de 1901, en Díaz (2010, p. 64).

${ }^{16}$ Álvarez de Sotomayor, Fernando, "Recuerdos de un viejo pintor”, p. 93. Manuscrito cedido por la familia del artista al autor de correspondencia de esta publicación.
} 
Ilustrado, en donde lo acusa de ser "un pintor-fotógrafo", a propósito del cuadro "La fundación de Santiago"17; crítica que realiza, precisamente, cuando esta obra estaba siendo exhibida en París en la Exposición Universal de 1889.

Sin embargo, las polémicas más conocidas sobre la fotopintura fueron aquellas que tuvieron como protagonistas a Juan Francisco González (1853-1933), una de las figuras emblemáticas en el campo cultural chileno hacia fines del siglo XIX y comienzos del XX, y a algunos medios de comunicación de la época.

González fue un maestro carismático y su ascendiente fue claro y potente, especialmente en las generaciones más jóvenes que se alineaban bajo convicciones artísticas más modernas. Su amplia labor como maestro, más algunas de sus intervenciones tales como la conferencia titulada "La enseñanza del dibujo", recogida en los Anales de la Universidad de Chile (González, 1906, pp. 103-118), amén haber formado parte en algunos conglomerados locales vanguardistas, entre ellos el grupo Los Diez, le otorgaron la posibilidad como para pronunciarse con cierta autoridad sobre distintos aspectos del acontecer estético nacional. Su posición fue clara y categórica respecto del academicismo y, especialmente, sobre ciertos procedimientos técnicos vinculados con la fotografía que usaban algunos artistas para realizar sus cuadros.

En la historiografía artística local constan, al menos, dos polémicas que sostuvo en relación a trabajos de fotopinturas realizados por el artista W. H. Walton. Usando un tono bastante áspero y casi agresivo en sus planteamientos, como diría Antonio Romera (1951, p. 138), sus opiniones hacían eje en una antigua polémica que alineaba, de una parte, a los artistas y críticos vinculados con el academicismo, y de otra a aquellos que detentaban posiciones más rupturistas; "los impresionistas", como diría Romera (1951). La primera de estas confrontaciones está recogida en el artículo "El pintor Walton. Sus retratos i la prensa porteña", aparecido en el $\mathrm{N}^{\circ} 71$ de El Taller Ilustrado, el 14 de febrero de 1887. En ella González trata a su oponente, a este "seudo pintor inglés" ${ }^{18}$, como un ignorante. Tiempo más

\footnotetext{
${ }^{17}$ El escultor señala: "Las figuras del cuadro de $<$ Valdivia $>(\ldots)$ no podían ser más rijidas ni mas anti-artísticas. Puede que su autor no las haya fotografiado en la tela; pero en todo caso, ellas dicen bien que el señor Lira es pintor fotógrafo i nada más, pues ignora en absoluto las reglas de la composición, tan indispensables en un cuadro histórico" (Blanco, 1889b).

18 "Voi, pues, a contestar una vez por todas las continuas bravatas i provocaciones del seudo pintor inglés, i voi a demostrarle sin gran trabajo i con toda tranquilidad que ni profesa ni conoce siquiera el arte de que se cree acaso gran representante" (González, 1887).
} 
tarde, y por información que recogemos del trabajo de Wenceslao Díaz ${ }^{19}$, el debate se enciende nuevamente a raíz de la publicación, en el diario $\mathrm{La}$ Unión de Valparaíso, de un elogioso artículo sobre un retrato de Remigio Salas, pintado por W. H. Walton. El articulista del periódico se deshace en elogios por el nivel del realismo con que había sido ejecutada la obra ${ }^{20}$. La actitud crítica de González frente a este nuevo escrito recrudece y en un tono fuerte, y bajo el pseudónimo de Araucano, descarga pesada artillería sobre el laudatorio texto, calificando a sus autores, entre otros epítetos, como "pordioseros de alabanzas"21. Estos planteamientos del maestro impresionista representaban en su época, con seguridad, a una escasa minoría, ya que la mayor parte de los artistas, el propio Estado y la clase dirigente del país, presente en las distintas comisiones que estaban detrás del sistema artístico local, valoraban todavía un modelo artístico cuyos repertorios iconográficos y estéticos se vinculaban con la tradición académica europea. Este modelo se había institucionalizado en el país a través de la enseñanza de la pintura y escultura, las colecciones oficiales, los salones, y la escritura artística. En este contexto entendemos la réplica de la que fue objeto el planteamiento de nuestro pintor y aquellos calificativos que lo tildaron de "bohemio", "maniático" e "impresionista"22.

${ }^{19}$ Polémica recogida en Díaz (2004, pp.145-49).

${ }^{20}$ La publicación en una de sus partes señala: "En actitud natural y tranquila, con una expresión llena de vida, el Sr. Salas tiene en su mano un cigarrillo, en que uno cree que puede encender su propio cigarro, según es la verdad del pequeño disco de fuego que en él brilla, y la ligera nubecilla de humo azulejo que de él se desprende". La Unión, Valparaíso, 24 de abril de 1894.

21 "Una obra de arte. De tal puede calificarse un jeneroso artículo de crónica de La Unión del 24 último y en el que un no menos jeneroso escritor endilga su laudatoria de pacotilla al autor de dos retratos de fotopintura que merced a nuestra indolencia se exhiben sin escándalo en una de la vidrierías de la calle de Esmeralda". "Y no menos anchas de tragaderas que el público deben ser los susodichos cronistas para dejarse embaucar por estos pordioseros de alabanzas, que para lograr reputación asaltan las imprentas sin perdonar ocasión cada vez que han hecho la hazaña de iluminar en tela la fotografía agrandada con cámara solar". González, J. (1894) El Heraldo, 2 de mayo.

${ }^{22}$ La réplica de La Unión no se dejó esperar: "Vagan por ahí, a falta de ocupación, dos o tres bohemios que se llaman pintores y además pintores impresionistas, pero que no sienten o manifiestan otras impresiones que las del despecho, cada vez que la crítica elogia las obras de los verdaderos artistas", y agrega: "Uno de esos tipos nos embiste desde el último rincón de El Heraldo, y nos revela claramente qué clase de impresiones son las que le dominan. ¿A que discutir con esos maniáticos? Puesto que el público da a sus esperpentos la sanción que merecen, sería crueldad excusada repetirles que en vez de embadurnar telas de que nadie hace caso, deberían dedicarse a pintar puertas y ventanas. Un pelotón de pintura arrojado sobre una tela, y decorado por un impresionista con el nombre de árbol, de agua, de retrato o de cualquier otra cosa, no es arte; y un remitido publicado en un diario para dar desahogo al despecho, no es juicio crítico". Ver Díaz (2004, p. 146).

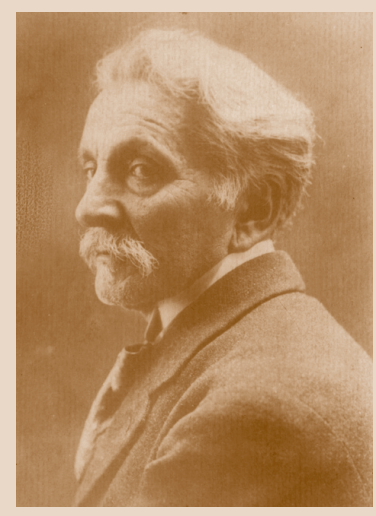

J. F. González 


\section{CONCLUSIÓN}

Las explicaciones acerca del cómo y por qué se producen estas desavenencias en el campo artístico nacional en este periodo pueden ser muchas y variadas. Quizá podamos encontrar algunas en la propia naturaleza del trabajo creativo, siempre expuesto al arbitrio y opinión de terceros; a distintas sensibilidades respecto de un modelo estético; a circunstancias generacionales o, en algunos casos, al peso y la injerencia de los personalismos.

De otra parte, el desarrollo de las distintas instituciones y actividades artísticas de la vida nacional en este periodo no se articuló desde una política explícita. Al respecto -y mirado el campo artístico- hubo más convicción que planificación, más voluntad que estrategia, más personalismo que democracia. Frente a la inexistencia de una instancia reguladora, las decisiones en este ámbito quedaron expuestas al voluntarismo y a los personalismos, que actuaban tanto al interior como fuera del campo estético y cultural. En ausencia de un marco ordenador, la política se hace explícita a partir de acciones formales y administrativas. A modo de ejemplo, en las asignaciones presupuestarias, en las obras que se adquieren, en las becas que se conceden, en los artistas que se contratan, en el nombramiento de profesores y directivos, en la integración de las comisiones y jurados de los salones, entre otros aspectos. En todo ello, el Estado expresa una ideología y una voluntad. Se trata de una política que toma cuerpo en la praxis, que opera en un marco ideológico difuso, marcado por criterios y valoraciones exógenas, por demandas coyunturales y, especialmente, al tenor de personalismos.

En este contexto los debates y las polémicas se empoderan en el sistema y de ello da cuenta el registro escritural. Al revisar la producción historiográfica de la época constatamos que, en muchos casos, los escritos de arte hacen eje en estas desavenencias, detrás de las cuales podemos inferir argumentos de todo tipo y, por sobre ello, el afán de algunos artistas de hegemonizar con su palabra y ascendiente un escenario estrecho y disputado. De otra parte, detrás del conflicto intuimos también los protagonismos individuales y ciertas cuestiones de origen social, que se presentan a veces con más fuerza que algunos eventuales desacuerdos en el plano ideológicoestético. De este modo, detrás de aquella frase de Amunátegui "Hijo de una familia de cortas proporciones" (1849, p. 46), cuando se refiere al malogrado Antonio Gana ${ }^{23}$, hay más que una casualidad.

${ }^{23}$ Antonio Gana (1822-1846) partió a Europa en 1842 becado por el gobierno chileno con la idea de que a su regreso fundara una instancia de formación artística académica. Murió en el barco cuando regresaba a nuestro país. 
El espacio escritural, quizá el campo de batalla de las confrontaciones, nos provee la mejor información para conocer los trasfondos, el alcance y la profundidad de estos enfrentamientos. En las publicaciones periódicas de la época, en las cartas, en las actas de las distintas entidades corporativas e, incluso, en algunos documentos oficiales, queda tramada esta otra historia, que nos habla con más elocuencia acerca de las pasiones y las convicciones que tuvieron sus protagonistas.

\section{REFERENCIAS}

Álvarez de Sotomayor, F. (s.f.). "Recuerdos de un viejo pintor". Memorias inéditas en poder de la familia.

Amunátegui, M. L. (1849). “Apuntes de lo que han sido las Bellas artes en Chile". Revista de Santiago, tomo tercero. Santiago: Imprenta Chilena.

Balmaceda Toro, P. (1889). Estudios y ensayos literarios. Santiago: Imprenta Cervantes.

Blanco, A. (1912). Biografía del escultor Don José Miguel Blanco. Santiago: Imprenta Cervantes.

Blanco, A. (1930). "Biografía del escultor Nicanor Plaza". Revista Chilena de Historia y Geografía, tomo LXVII, No 71.

Blanco, J. M. (1879). "Proyecto de un Museo de Bellas Artes". Revista Chilena, tomo XV, Santiago: Imprenta de la República.

Blanco, J. M. (1887). “¿Quién es tu enemigo?”. El Taller Ilustrado, año III, No 100, Santiago de Chile, 3 octubre.

Blanco, J. M. (1887). "El salón de la Unión Artística en la Quinta Normal de Agricultura". El Taller Ilustrado, Santiago de Chile, 28 de febrero.

Blanco, J. M. (1889a). "Lasciati Ogni Speranza..." ("Los que aquí entráis, perded toda esperanza"). El Taller Ilustrado, año IV, $\mathrm{N}^{\circ}$ 179, Santiago de Chile, 13 de mayo.

Blanco, J. M. (1889b). "La fotografía en la pintura". El Taller Ilustrado, año IV, No 182 , Santiago, 1 julio.

Bourdieu, P. (2002). Las reglas del arte, génesis y estructura del campo literario. Barcelona: Anagrama, Colección Argumentos.

Carvacho, V. (1983). Historia de la escultura en Chile. Santiago: Ed. Andrés Bello.

Cicarelli, A. (1849). “Origen y progreso de las Bellas Artes”. Discurso pronunciado con motivo de la apertura de la Academia de Pintura, el 7 de marzo de 1849. Anales de la Universidad de Chile, t. VI, pp. 105-117.

De la Maza, J. (2010). "Por un arte nacional. Pintura y esfera pública en el siglo XIX chileno". Ciencia - mundo, orden republicano, arte y nación en América. Santiago: Centro de Investigaciones Barros Arana - Editorial Universitaria. 
Díaz, W. (2004). Juan Francisco González. Cartas y otros documentos de su época. Santiago: Ril Editores.

Díaz, W. (2010). Bohemios en París, Epistolario de artistas chilenos en Europa (1900-1940). $1^{\text {a }}$ edic. Santiago: Ril Editores.

Domeyko, I.(1874). Carta al Ministro de Instrucción Pública, Santiago, del 20 de junio. Santiago: Archivo Nacional, Fondo Ministerio de Educación, vol. 290.

González, J. (1887). “El pintor Walton. Sus retratos i la prensa porteña”. El Taller Ilustrado, $\mathrm{N}^{\circ} 71$ de 14 de febrero.

González, J. (1906). "La enseñanza del dibujo". Anales de la Universidad de Chile, t. CXIX, Sem. $2^{\circ}$.

Grez, V. (1889). “Les beaux arts au Chili”. Catálogo Exposición Universal de París (Sección Chilena). París.

Herrera, P. (2014). "Pedro Lira y José Miguel Blanco: Sus 'luchas artísticas' y la articulación de un sistema del arte en Chile". El Sistema de las Artes, VII Jornadas de Historia del Arte, MHN, Santiago de Chile.

Lira, P. (1865). "Las Bellas Artes en Chile". Revista Ilustrada, Santiago de Chile.

Lira, P. (1883, julio 3). "Museo Nacional i Exposiciones de Bellas Artes", diario La Época, Santiago de Chile.

Lira, P. (1887). Carta al Ministro de Instrucción Pública, Santiago, 20 abril. Archivo Nacional, Fondo Ministerio de Educación, vol. 685.

Lira, P. (1902). Diccionario biográfico de pintores. Santiago: Imprenta Encuadernación y Litografías Esmeralda.

Pereira Salas, E. (1992). Estudios sobre la historia del arte en el Chile republicano. Santiago: Ediciones Universidad de Chile, Fundación Andes (póstumo).

Richón Brunet, R. (1912). "Don Pedro Lira”. Revista Selecta. Santiago, Editorial Zig Zag, Año IV, $\mathrm{N}^{\circ} 1$ mayo.

Romera, A. (1951). Historia de la pintura chilena. Santiago: Editorial del Pacífico S.A.

Zegers, R. (1981). Juan Francisco González, Maestro de la pintura chilena. Santiago: Ediciones Ayer. 